\title{
Utilizing Aloof-beam Vibrational EELS for the Detection of Hydrogen and Defect Heterogeneity in Carbon Nitrides
}

\author{
Diane M. Haiber ${ }^{1}$, Kartik Venkatraman ${ }^{1}$ and Peter A. Crozier ${ }^{1}$ \\ 1. School for Engineering of Matter, Transport \& Energy, Arizona State University, Tempe, Arizona \\ 85287-6106, USA
}

Layered carbon nitrides have recently emerged as metal-free, visible-light absorbing semiconductors with growing interest as photocatalysts for hydrogen production [1]. While transmission electron microscopy (TEM) and electron energy-loss spectroscopy (EELS) are powerful tools to characterize nanoscale features in (photo)catalysts, their application to layered carbon nitrides is difficult due to radiation damage. Graphitic carbon nitride $\left(\mathrm{g}-\mathrm{CN}_{\mathrm{x}} \mathrm{H}_{\mathrm{y}}\right)$ compounds, based on layers of amine-bridged heptazine $\left(\mathrm{C}_{6} \mathrm{~N}_{7}\right)$ chains [2], differentiated by their residual H-content, represent a wide-ranging class of material with ill-defined variation in structure. Molten salt synthesis routes have yielded crystalline, layered carbon nitrides based on triazine $\left(\mathrm{C}_{3} \mathrm{~N}_{3}\right)$ motifs with correspondingly less $\mathrm{H}$-content [3]. These are referred to as poly(triazine imide) with intercalated halide ions (such as $\mathrm{Li}$ and $\mathrm{Cl}$ ), or $\mathrm{PTI} / \mathrm{LiCl}$. Amine (i.e. $\mathrm{N}-\mathrm{H}_{\mathrm{x}}$ ) content in both $\mathrm{g}-\mathrm{CN}_{\mathrm{x}} \mathrm{H}_{\mathrm{y}}$ and $\mathrm{PTI} / \mathrm{LiCl}$ are correlated to changes in photocatalytic hydrogen evolution under visible-light, suggesting these defects can regulate optical absorption or charge transfer kinetics depending on how the host structure is modified. To enhance photocatalytic performance, carbon nitrides are often functionalized with $\mathrm{Pt}$ which act as hydrogen evolution cocatalysts. More recently, chemical deposition approaches have yielded single-atom co-catalysts with correspondingly higher photocatalytic performance [4]. While infrared (IR) spectroscopy enables comparison of H-content between carbon nitrides, it lacks the spatial resolution needed for unambiguously correlating defects with catalytically relevant sites.

Here, we utilize vibrational EELS to locally probe bonding in $\mathrm{g}-\mathrm{CN}_{\mathrm{x}} \mathrm{H}_{\mathrm{y}}$ and PTI/LiCl, which are expected to contain a high and low degree of chemical heterogeneity, respectively. Figures 1(a)-(b) compares low dose rate TEM images of $\mathrm{g}-\mathrm{CN}_{\mathrm{x}} \mathrm{H}_{\mathrm{y}}$ and $\mathrm{PTI} / \mathrm{LiCl}$. While PTI/LiCl possesses hexagonal inplane symmetry as evidenced in the corresponding FT (inset, Figure 1(b)), g- $\mathrm{CN}_{\mathrm{x}} \mathrm{H}_{\mathrm{y}}$ demonstrates limited long-range order. To mitigate radiation damage during vibrational EELS acquisition, an 'aloofbeam' configuration is employed, wherein the convergent electron beam is placed several nanometers outside the specimen. Figure 1(c)-(d) compares several vibrational EEL spectra from $\mathrm{g}-\mathrm{CN}_{\mathrm{x}} \mathrm{H}_{\mathrm{y}}$ and PTI/LiCl, respectively, from which the $\left(\mathrm{N}-\mathrm{H}_{\mathrm{x}}\right) /\left(\mathrm{C}-\mathrm{N}\right.$ ring) bonding ratios were calculated. In $\mathrm{g}-\mathrm{CN}_{\mathrm{x}} \mathrm{H}_{\mathrm{y}}$, amine content is found to vary locally up to $27 \%$. Upon probing small volumes through vibrational EELS, $\mathrm{C} \equiv \mathrm{N}$ defects in $\mathrm{g}-\mathrm{CN}_{\mathrm{x}} \mathrm{H}_{\mathrm{y}}$ are also revealed. Compared to the corresponding low dose STEM images, some of which are displayed in Figure 1(e)-(h), aloof-beam vibrational EELS provides useful information for analyzing heterogeneity in polymeric, disordered materials such as $\mathrm{g}-\mathrm{CN}_{\mathrm{x}} \mathrm{H}_{\mathrm{y}}$.

Pt-loaded g- $\mathrm{CN}_{\mathrm{x}} \mathrm{H}_{\mathrm{y}}$ was obtained through a chemical deposition route in which $\mathrm{NaBH}_{4}$ is used as a reducing agent for aqueous $\mathrm{Pt}^{4+}$ ions to form single-atom dispersions, as shown in Figure 2(a) [4]. Figure 2(b) compares the IR absorption spectra for bare and as-synthesized $0.5 \mathrm{wt} \% \mathrm{Pt} / \mathrm{g}-\mathrm{CN}_{\mathrm{x}} \mathrm{H}_{\mathrm{y}}$, showing a significant increase in intensity between $1930-2400 \mathrm{~cm}^{-1}$ which may be attributed to $\mathrm{C} \equiv \mathrm{N} / \mathrm{C} \equiv \mathrm{C}$ species. While single atom dispersions can be obtained, the $\mathrm{g}-\mathrm{CN}_{\mathrm{x}} \mathrm{H}_{\mathrm{y}}$ support appears to be altered which may in turn affect photocatalytic performance. Similarly, an aloof-beam approach may be exploited to identify the spatial distribution of such defects resulting from this method of single-atom Pt loading. 
References:

[1] X. Wang et al. Nat. Mater. 2009, 9, 76-80.

[2] B. Lotsch et al. Chem. Eur. J. 2007, 13, 4969-80.

[3] E. Wirnhier et al. Chem. Eur. J. 2011, 13, 3213-21.

[4] Z. Chen et al. Adv. Funct. Mater. 2017, 1605785.

[5] Support from the U.S. DOE (DE-SC0004954), National Science Foundation (CHE-1508667), use of AC-TEM and FT-IR equipment within the LeRoy Eyring Center for Solid State Science at ASU, and use of the K2-IS detector courtesy of Gatan are gratefully acknowledged.
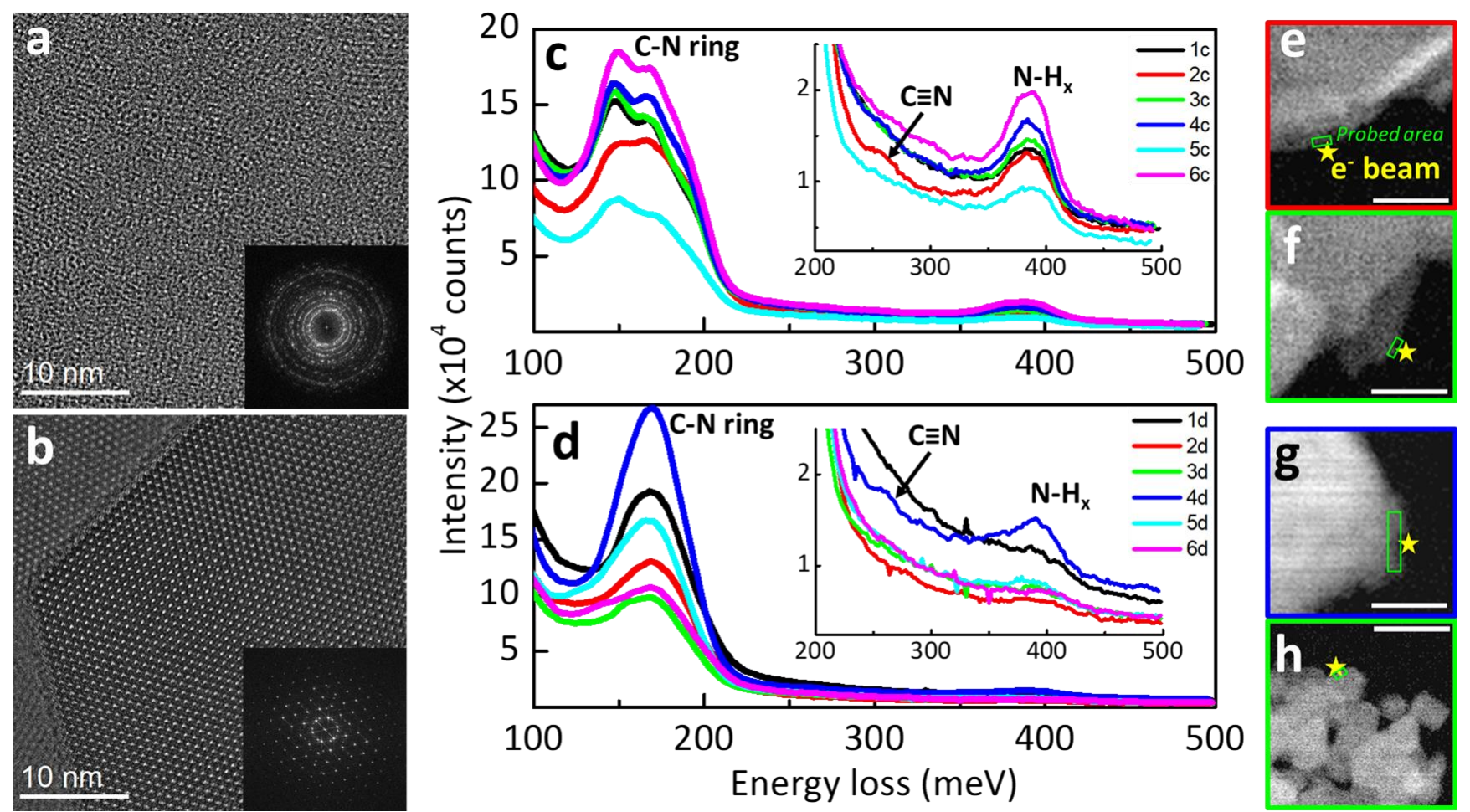

Figure 1. Low dose rate $\left(<20 \mathrm{e}^{-} / \AA^{2} / \mathrm{s}\right)$ TEM images of (a) $\mathrm{g}-\mathrm{CN}_{\mathrm{x}} \mathrm{H}_{\mathrm{y}}$ and (b) PTI/LiCl, both viewed approximately perpendicular to the basal planes. Several aloof-beam vibrational EELS spectra for (c) g$\mathrm{CN}_{\mathrm{x}} \mathrm{H}_{\mathrm{y}}$ and (d) PTI/LiCl. ADF-STEM images showing the e-beam position (yellow star) and probed area (green rectangle) corresponding to spectrum (e) $2 \mathrm{c}$, (f) $3 \mathrm{c},(\mathrm{g}) 4 \mathrm{~d}$, and (h) $3 \mathrm{~d}$; scale bars=50 $\mathrm{nm}$.
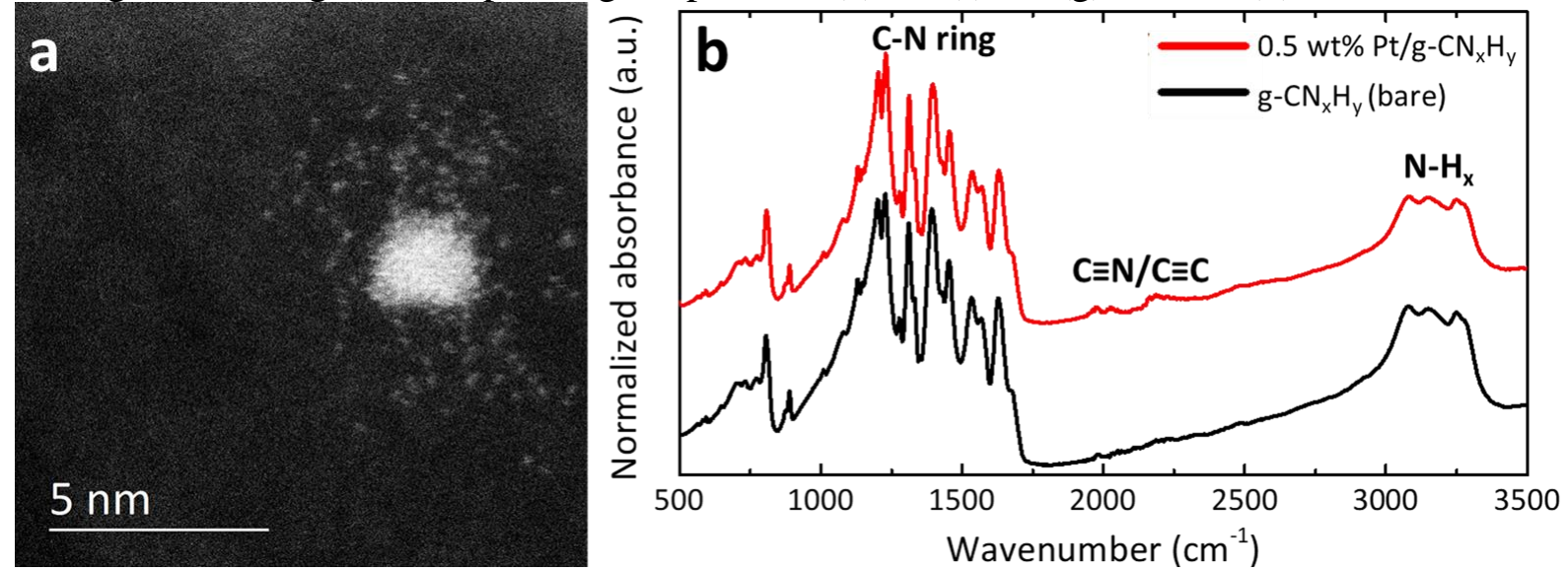

Figure 2. (a) An ADF-STEM image of the Pt-loaded $(0.5 \mathrm{wt} \% \mathrm{Pt}) \mathrm{g}-\mathrm{CN}_{\mathrm{x}} \mathrm{H}_{\mathrm{y}}$, confirming single-atom dispersions, and (b) IR absorption spectra for bare and Pt-loaded g- $\mathrm{CN}_{\mathrm{x}} \mathrm{H}_{\mathrm{y}}$. 